\title{
An Analysis of the Influence Mechanism of the Cultural Intelligence of Expatriate on Expatriate Performance
}

\author{
Liangliang Wang \\ International Business School \\ Yunnan University of Finance and Economics \\ Yunnan, China \\ 1015792105@qq.com \\ Ying Zhang* \\ 1. International Business School \\ Yunnan University of Finance \& Economics
}

\author{
2. School of Management and Marketing \\ Charles Sturt University, Wagga Wagga, Australia \\ angie@ynufe.edu.cn \\ Rui Hu \\ Yunnan University of Finance and Economics \\ Yunnan, China \\ 867117267@qq.com
}

\begin{abstract}
The paper discusses the influence of cultural intelligence on expatriate performance in view of the mediating role of expatriate adaptation between cultural intelligence and expatriate performance, and moderating effect of cross-cultural conflict management styles between the covering relationships. It is proposed that cooperative cross-cultural conflict management style has positive effects on expatriate adaptation, competitive cross-cultural conflict management style has negative effects on expatriate adaptation, which in turn will affect expatriate performance.
\end{abstract}

Keywords-expatriate management; cultural intelligence; expatriate maladjustment; cross-cultural conflict management; expatriate performance

\section{INTRODUCTION}

The correct choice of expatriate personnel is a critical antecedent for the expansion of multinational enterprises' cross-border business and the rapid development of enterprises. However, many cases of failure of corporate assignments remain high, which directly affects the external expansion of company. For example, in the context of the Belt and Road strategy, according to the website of Yunnan Foreign Labor Service Cooperation, by the end of August 2016, Yunnan Province has amassed 97,718 laborers of various types, accounting for approximately $0.22 \%$ of the total population of the province. As a result, the demand for expatriates has also been greatly increased. However, the expatriate failure rate has been numerated as from $16 \%$ to $40 \%$ and incidents of cultural conflicts are on the rise. Countries in South Asia and Southeast Asia have different cultural backgrounds and customs. The demand of member of expatriates is being increasing and which made it more difficult for them to succeed. Dealing with cultural differences and recognizing how and when these differences are related is a constant challenge. The issue of the selection and invocation of expatriates cannot be fundamentally resolved, which has an important impact on the improvement of expatriate performance. So far, the research on

\footnotetext{
*Corresponding author
}

dispatching management at home and abroad has been rapidly developed and has achieved certain achievements. Western scholars' research on the management of foreign administration is more systematic and comprehensive, but this conclusion may not be universally applicable in China. How to improve the success rate of the company's expatriate and the performance of the expatriate, which is not only an internal problem in the internationalization enterprise but also a problem that scholars in related fields have continuously paid attention to and studied.

Therefore, this paper will use the "stimulus-cognitionresponse" model of cognitive behavior theory as the theoretical framework in the cross-cultural context based on the actual needs of large-scale enterprises in Yunnan Province under the One Belt One Road Strategy Background. Mehrabian and Russel proposed the SOR theory based on psychology in 1974, which was developed from the input-output model. Because input-output can only analyze and express explicit external stimuli and results, it cannot present the inner consciousness and mental perception of the stimulus, in order to solve this problem, the stimulus-cognitive-response model came into being. According to the quality of expatriates and the requirements of the expatriate work, match them appropriately. On this basis, to understand the needs of expatriates, expatriate managers use incentives to stimulate employee demand, according to the different characteristics of employees, expatriate managers adopt different cross-cultural conflict management methods, improve the adaptability and cognition of expatriates, so that employees' behaviors and organizational goals are consistent, so as to improve the performance of expatriates. Based on the cultural characteristics of different host countries, different host countries have put forward different requirements for expatriates. Based on this, variables such as cultural intelligence, cross-cultural conflict management, expatriate adaptation are pertinent to expatriate performance. This article built on previous research theories, combined the status quo with existing problems of the management of the key enterprises in Yunnan Province, aiming 
to explore the influencing factors of the outbound performance of the mechanism.

\section{LITERATURE RIEVIEW}

\section{A. Review of Expatriate Adaptation}

Cross-cultural adaptation theory is based on early cultural assimilation and cultural shock theory. Culture adapts to a onedimensional model, because it cannot explain the individual's adaptability for both cultures. Later, Berry proposed a twodimensional model. Subsequently, Berry [1] summed up the previous studies and put forward the theory of cultural adaptation. As the theory of cross-cultural adaptation are improved constantly. Black \& Mendenhall [2] proposed an adapted social three-dimensional model for expatriates. Triandis [3] proposed the theory of individual-collectivism. The cultural framework theory of Trompenaars and Hofstede [4]. The theory of cultural dimension, and the system theory advocated by a group of scholars today. In the development of measurement tools, Black was one of the earliest scholars to carry out empirical research on adaptation. He divided the assignments into three dimensions: general adaptation, interactive adaptation, and job adaptation. General adaptation refers to the overall psychological comfort level (including food, weather, and living standards) of the expatriate personnel in the host country's cultural environment. Interactive adaptation refers to the psychological comfort of expatriates in the host country's culture when communicating with local people; Adaptation refers to the level of psychological comfort of expatriates for work values, standards, and expectations of the host country.

\section{B. Review of Cultural Intelligence Research}

The earliest cultural intelligence structure is threedimensional, and Earley and Ang [5] believe that cultural intelligence includes three dimensions: cognitive, motivational, and behavioral. Cognition includes analogy, pattern recognition, statement, self-awakening, and external scanning. Motivation includes enhancing value and comprehensive ability, persistence, goals, and efficacy; behavioral features include: ability of acquiring new knowledge and rules, conventions and skills. Thomas [7] proposed a different three-dimensional cultural intelligence structure from different perspectives. These three dimensions include knowledge, behavior and vigilance. Knowledge is the principle that should be grasped in the recognition of culture and cross-cultural communication, identify the types of culture faced, clearly distinguish the characteristics of the host country's culture, and explore this feature how affects the behavior of expatriates. These acts are based on knowledge and alertness. Expatriates adapt to specific cultural environments by changing their behavior. Alertness refers to the fact that when an expatriate enters an unfamiliar environment, he or she will have a basic sense of vigilance by continuing to focus on the external environment and the internal environment he is in. Thomas emphasizes that vigilance plays a bridge role in these three dimensions, and it is also a key difference from other three-dimensional models of cultural intelligence. With the deepening of the study of cultural intelligence, Earley and Ang [5] proposed the fourdimensional structure of cultural intelligence. These four dimensions include: metacognition, cognition, motivation and behavior. Metacognitive cultural intelligence is " thinking above thinking", that is, the individual's understanding and strategies for monitoring and using personal cognitive knowledge, which include planning, self-monitoring and the use of cognitive strategies [6]. Cognitive cultural intelligence refers to individuals knowing for the culture and what cultural differences and how different cultures influence behavior. This requires a rich accumulation of social and cultural knowledge, which include politics, culture, economy, religion, society and relationship. Motivation Cultural intelligence refers to the willingness of expatriates to face and interact with different cultures and the desire to persist and solve them in the face of conflict situations [6]. The close relationship between expatriate adaptation and motivation has been widely demonstrated in various studies [8]. Behavioral cultural intelligence refers to "a good behavioral instruction system" [9]. According to this system, expatriates can make sensible choices, including linguistic and non-verbal behaviors that adapt to situations in interactions. People with a high level of cultural intelligence have a strong ability of imitating [7], which is the unconscious mechanical interaction [10]. The four-dimensional model of cultural intelligence is currently rarely criticized. The only criticisms came from HampdenTurner and Trompenaars [11].

\section{Review of Cross-cultural Conflict Management Research}

The related research on cross-cultural conflict management in foreign countries is based on the theoretical basis of management grid. Foreign scholars divided the impact of cultural conflict on expatriate into two parts. On the one hand, it is a study on the negative effects of conflict, on the other hand, it is research on the positive effects of conflict. The representatives of studies on the negative impact of conflict are Gladstein, Wall and Nolan [12]. The main aspects of the study include how conflicts affect the production efficiency of enterprises and employees' satisfaction [13]. Micro-level influences include the stereotype of employee thinking, responsiveness, laxness and reduced attention to customers; Macro-level impacts include the failure of the company to achieve its goals and the loss of business opportunities. Jehn, Leung\&Tjosvold, Tjosvold [14] et al. believed that conflicts would have a positive impact on employees and conducted empirical research, suggested that conscious cooperative conflict management strategies and constructive debates can be improved, which can improve employee performance and organizational efficiency. All of the above belong to the study of conflict management under the same cultural background. Kirkbride, Tang, and Westwood, Francis, and Walls [15] have conducted empirical studies on conflict management in different cultural contexts. These researchers believe that Asians tend to choose to evade when dealing with conflicts, while Westerners Willing to face the conflict directly. Regarding the conflict response mechanism, many foreign scholars have summarized the research results of recent years: Rahim [16] divided the conflict management methods into five types: avoidance, accommodation, competition, cooperation, and compromise; Tjosvold et al. [14] divided the types of conflict management methods into cooperation, competition and avoidance. This study is based on the five-dimensional model of conflict management by Rahim [16]. Among these 
five management methods, this study focuses on the two conflict management methods: cooperation and competition.

\section{Review of Research on Expatriate Performance}

At present, scholars' research on the performance of expatriate is mainly concentrated on job performance [17]. The performance of expatriates was firstly interpreted as the extent to which they completed their work tasks, it reflect that extent to which expatriate can achieve position requirements, which refers to the sum of the work result, working behavior and working attitude of the expatriate during the assignment. Relevant scholars have added that the expatriate performance cannot only be limited to job performance, but should also include indicators for measuring work attitudes, such as expatriate satisfaction and early return intentions. In this paper, the expatriate performance refers to the behavior and results of expatriates in the cross-cultural background, through efforts to overcome difficulties, adapt to the local work environment, and then achieve the business development goals of the company. Based on previous studies, this study expands the dimensions of expatriate performance into three aspects: task performance, situational performance, and attitude performance. However, whether expatriates can expand their business abroad and improve their expatriate performance, which depends on the cultural intelligence and level of adaptation of expatriates, as well as management methods in the face of conflicts.

\section{RESEARCH HYPOTHESIS}

\section{A. The Direct Influence of Cultural Intelligence on Expatriate Performance}

For the domestic and foreign scholars' research on the expatriate performance, who often attribute the differences in the expatriate performance to individualities and abilities of the expatriates and conducted empirical research. This also confirmed the hypothesis. However, some scholars believe that while relatively stable personality traits (such as extroversion and initiative) have a certain impact on the performance of the expatriates, the concept of cultural intelligence itself includes the personality traits of expatriates and is more dynamic. Therefore, this paper proposes to use cultural intelligence to predict the assignment performance of expatriates. Wang et al. [18] conducted an empirical study of individual cross-cultural adaptation from the perspective of cultural intelligence to verify the validity of the cultural intelligence scale and revealed a significant positive correlation between motivational cultural intelligence and cross-cultural adaptation. For expatriates performance and interactive adaptation, there is some predictability. Summarizing the previous research experience, we believe that individuals with different cultural intelligence often show different levels of adaptability in host countries and thus achieve different performance in the field. Therefore, it is highly probable that the higher the expatriate's cultural intelligence, the better the expatriate performance achieved. Based on the above analysis, this paper makes the following proposition:

P1: There is a significant positive correlation between the expatriate's cultural intelligence and the expatriate performance.

\section{B. The Intermediary Role of Expatriate Adaptation}

Expatriate adaptation is essentially cross-cultural adaptation in reviewing literature of sociology and economics [19]. The early studies on cross-cultural adaptation focused on the cultural changes in the cultural contacts between immigrant groups and host countries [18]. Expatriate adaptation is divided into psychological and cultural adaptation and social and cultural adaptation. The theory of job role change argues that the individual's adaptation to the new work environment affects the job outcome of the expatriate individual [20]. Zhang \& Zhou [21] research shows that cultural intelligence has a positive correlation with expatriate adaptation. The higher the cultural intelligence, the expatriates often shows high cultural adaptability. Expatriate workers who are better adapted to the assignments that are more confident in the work they have done. They have shown a positive attitude and achieved better results. If expatriates get good assignment performance, high cultural intelligence is an indispensable factor, but this is not a necessary and sufficient condition. Therefore, we believe that expatriate adaptation as an intermediary variable has an intermediate role between cultural intelligence and expatriate performance::

P2: In the process of cultural intelligence affecting the performance of expatriates, expatriate adaptation plays an intermediary role.

\section{The Mediating Role of Cross-cultural Conflict Management Styles (CCMS)}

Expatriate adaptation is an important intermediary variable in the process of expatriation. So for the research on the performance of expatriates is of great significance. Therefore, in order to facilitate the study of the relationship between cultural intelligence and expatriate adaptation, cross-conflict management is introduced as a mediating variable for cultural intelligence and expatriate adaptation. In the process of crosscultural conflict management of multinational companies, according to the sequence of development stages, the process of cross-cultural conflict can be divided into three phases: the input phase, mainly referring to the generation of cross-cultural conflicts; the conflict handling phase, how to use scientific means to adopt appropriate and harmonious processing methods, and the output stage, mainly refer to the effective realization of cross-cultural management goals, the increase in the organizational performance of multinational companies, and the stable management and management of the company [22]. As for the influence of cultural intelligence on the expatriate performance, which is likely to be related to the conflict management style adopted by individuals when conflict occurs. (1) individuals with high cultural intelligence can make choices of appropriate management conflict strategies through his high-level cognitive and cultural intelligence. (2) individuals with high cultural intelligence are more likely to choose cooperative strategies and avoid competitive strategies to ensure effective prevention the expatriate conflicts; (3) individuals with high cultural intelligence are more likely to choose other ways in the crosscultural conflict, they trend to maintain cooperation and even constantly improve for the purpose of adapting the results of their assignments. On the contrary, if individuals with low cultural intelligence tend to adopt competitive conflict 
management methods, which is lilkely to make the performance outcome worse. In the face of conflict when they are working, the expatriate personnel adopt different methods of conflict management which will have different degrees of impact on the achievement of the company's goals. The conflict manager's approach for managing conflict is therefore largely depends on the level of cultural intelligence of expatriates. Hence, we believe that cross-cultural conflict management is not only a mediating variable between cultural intelligence and expatriate adaptation, but also plays an intermediary role between cultural intelligence and expatriate performance. Therefore:

P3a: Cross-cultural conflict management plays an intermediary role between cultural intelligence and expatriate adaptation.

P3b: Cross-cultural conflict management plays an intermediary role between cultural intelligence and expatriate performance.

In summary, the conceptual framework of this paper is shown in Figure 1:

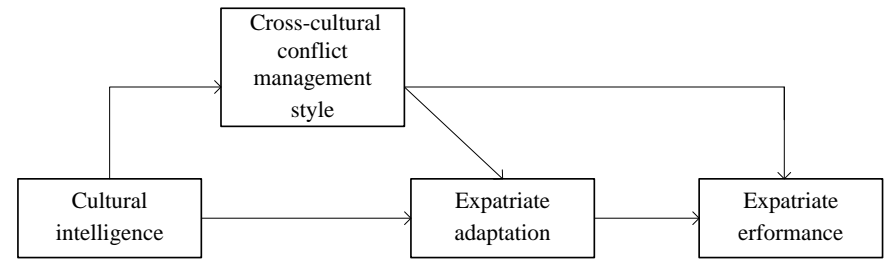

Fig. 1. Theoretical model

\section{CONCLUSION}

\section{A. Conclusion and Implication}

In the cross-cultural work environment, expatriates face a lot of work difficulties and obstacles, which is caused by the change of working environment, cultural environment and living environment, which will further lead to the negative attitude and frustration of expatriates. This phenomenon can lead to low organizational performance. At this stage, it is a critical period for the One Belt And One Road strategy. Chinese companies will seize this opportunity to "go global". The selection of expatriates is the key point for enterprises to achieve regional expansion. How to solve the problems of expatriates, formulate corresponding solutions and set selection criteria is of great importance to improve the performance of expatriates. Propositions drawn from our analyses can be summarized as follows: (1) Cultural intelligence can affect the results of expatriates' performance. For expatriates, the higher the cultural intelligence means that the better the expatriate performance. That is, there is a significant positive correlation between expatriate performance and cultural intelligence. (2) Expatriate adaptation has certain mediating effects between the performance of expatriates and cultural intelligence. Expatriate adaptation is an important way for cultural intelligence to play its role. This is also the main line of the influence mechanism of cultural intelligence on the expatriate performance. (3) Cross-cultural conflict management plays an intermediary role between cultural intelligence and expatriate performance. First of all, expatriates with high cultural intelligence can choose the appropriate management conflict strategy to improve their expatriate adaptation; Secondly, expats with high cultural intelligence are more likely to choose cooperative strategy rather than competitive strategy to ensure effective prevention of dispatched conflicts, on the contrary, due to the limitation of their cognitive level, expats with low cultural intelligence tend to adopt a competitive conflict management, which leads to the inadaptability of expatriats. Therefore, cultural intelligence of expatriates must be improved through training and education. (4) Cross-cultural conflict management is not only an intermediary variable between cultural intelligence and expatriate adaptation, but also plays an intermediary role between cultural intelligence and expatriate performance. This point of view is presented in this article and it is also the innovation point of this article. Therefore, Yunnan enterprises should pay full attention to the management of conflicts, and recognize the intermediary role of cross-cultural conflict management between cultural intelligence and expatriates performance. When Yunnan enterprises select expatriates, they should formulate Selection criteria so that they can increase the success rate of expatriate companies and thus enhance the company's expatriate performance.

\section{ACKNOWLEDGMENT}

Funding for this research was provided by National Natural Science Foundation of China under grants 71762033. The international collaborative research program and cooperation with Charles Sturt University in Australia is gratefully acknowledged. The assistance of Australian scholars Dr. Sophia X. Duan, Professor Mark Frost and Dr. Antony Bush are also acknowledged.

\section{REFERENCES}

[1] Berry. Intercultural relations in plural societies. Canadian Psychology, 40, 12-21.

[2] J. S. Black, M. Mendenhall. The U-curve adjustment hypothesis revisited: A review and theoretical framework [J]. Journal of International Business Studies, 1991, (2): 225-47.

[3] H. Triandis. Culture and social behavior [M]. New York: McGraw Hill, 1994.

[4] H. Hofstede. Culture's Consequences: International Differences in Work-related Values [M].Beverly Hills:Sage Publications, 1980.

[5] C. Earley, S. Ang, Cultural intelligence: Individual interactions across cultures [M]. Stanford, CA: Stanford University Press, 2003.

[6] P. C. Earley \& E, Mosakowski. Cultural intelligence. Havard Business Review, 2004, 82, 139-146.

[7] D. C. Tmoas. Domain and development of cultural intelligence. The importance of mindfulness. Group \& Organization Management, 2006, 31,78-99.

[8] Y. Zhang, Expatriate development for cross-cultural adjustment: Effects of cultural distance and cultural intelligence [J]. Human Resource Development Review, 2013, 12: 177-99.

[9] Tmoas, David C. and Inkson. Cultural IntelligencePeople Skills for Global Business. Berret-Koehler. New York.2004.

[10] Earlly. Redefining interactions across cultures and organizations: Moving forward with cultural intelligence. Research in Organizational Behavior, 24, 271-299.

[11] F. Trompenaars, Hampden-Turner, C. Riding the waves of culture: Understanding cultural diversity in business [M]. London: Nicholas Brealey, 1997.

[12] G. Hofstede,"The cultural relativity of the quality of life concept", Academy of Management Review, 1984, Vol. 9 No. 3, pp. 389 -98 . 
[13] Liang Wang, Xiongying Niu. Review and Prospect of Research on Foreign Adaptation [J]. East China Economic Management, 2018, 32(02): 176-184.

[14] D. Tjosvold. Conflict management for justice, innovation, and strategic advantage in organizational relationships [J]. Journal of Applied Social Psychology, 2010, 40(3): 636-65.

[15] P. S. Kirkbride. S. F.Y. Tang, and R. I. Westwood, "Chinese conflict Psychological influnces.” Organization Studies,1991, 12, 365-386.

[16] A. Rahim, N. R. Magner. Confirmatory factor analysis of the styles of handling interpersonal conflict: First-order factor model and its invariance across groups [J]. Journal of Applied Psychology, 1995, 80: 122-32.

[17] Redfieldr, Lintonr, Herskovits M J. Memorandum for the study of acculturation[J].American anthropologist, 1936, 38 (1) :149-152.

[18] H. Qiu, J. Wang*, et al., Nat. Commun. 4, 2642 (2013).
[19] Xiumei Shi, Hua Yu. Research on the Models and Approaches of Transnational Corporations' Effective Cross-cultural Management [J]. Cross-cultural Management, 2015, 3(01): 72-83.

[20] Lin Mao, Bingjun Hou. Analysis of Cross-cultural Conflict Managemen of Multinational Corporations [J]. Commercial Culture,2008(10):148

[21] Zhang, Y.,\& Zhou, W. An asymmetric cross-cultural perspective on the mediating role of conflict management styles in expatriation. International Journal of Conflict Management,28(05),592-616.

[22] Shaffer M A, Harrison D A. Expatriates'psychological withdrawal from international assignments: work, nonwork, and family influences [J] . Personnel Psychology, 1998, 51( 1) : 87-118.

[23] Hui Li ,Qun Wang, Research on the Impact of Out-of-Office Persons Cultural Intelligence on the Outcome Performance-Based on the Empirical Analysis of China's "Going Global" Company [J]. forecast, 2018, 37(02):1-8 